\title{
Survey on Rural Household Energy Consumption-Based on the Perspective of Poverty Alleviation in Hebei Province
}

\author{
Bo GAO ${ }^{1, a^{*}}$, Hong-Lin YUAN ${ }^{2, b}$ \\ ${ }^{1}$ Mechanical and Electrical Engineering College, Agricultural University of Hebei, Baoding, Hebei \\ 071000, China \\ ${ }^{2}$ Science and Technology Department, Hebei Scientific and Technical College, Baoding, Hebei, \\ 071000, China \\ agaobo@hebau.edu.cn, byuan7526@163.com \\ ${ }^{*}$ Corresponding author
}

Keywords: Survey, Energy Consumption, Rural Household, Poverty Alleviation.

\begin{abstract}
Poverty alleviation is a core task for building a harmonious society in contemporary China. Based on a survey on attitudes and behaviors of rural household energy consumption, the share of respondents in satisfaction on power supply, attention of energy saving and power bills take on roughly similar feature and no obvious relation between the individuals' opinion with their local economy level. The focus of targeted poverty alleviation should be poor families instead of economically backward counties.
\end{abstract}

\section{Introduction}

Poverty Alleviation in Hebei Province. Poverty eradication and shared development concept has become routine in China central and local policy systems. In 2013, President Xi firstly made the remarks on precise poverty alleviation project instead of indifferent poverty alleviation in conventional practices. The National Development and Reform Commission and the State Council Leading Group Office of Poverty Alleviation and Development have initiated "ten programs for precise poverty alleviation" and aimed to advocate and conduct a development-oriented approach in poverty alleviation. Precision in targeting with multiple ways not only provide financial support and assess both the effort and the measures of the officials. But furthermore, the behavior, attitude and willingness of the impoverished population should be attracted enough attention to guarantee the targeted poor empowered and to end poverty successfully.

It is reported that China had 70 million people living below the nation's poverty line at the end of 2014. As one of the ten poverty alleviation programs, energy program has twofold implications for poverty elimination in targeted rural regions: energy poverty that means no enough commercial fuel to support residents living or agricultural production; poverty elimination by energy production projects by lunar power project or wind power project. Energy is widely recognized as an essential source for social development and the characteristics of rural household energy consumption reflect inherent properties of local economic development and the living quality of the poor population.

Rural energy issue. Rural energy issue, as an exclusive term for developing countries, can be still a topic to attract to eyes of scholars, investors and entrepreneurs depending on a global perspective and focus on requirement and supply capacity of energy. According to the World Bank's data, there are still two billion people need modern forms of energy supply (Rischard, 2005). But rural energy issue in China today, especially for Hebei province-which is surrounding two of four municipality cities-, has profound significance on social effect and environment effect. Accompanying with the country's rapid industrialization environmental crisis, especially air pollution has become a top one issue in front of publics. Most energy consuming behaviors are part of households' inconspicuous habits which will influence the final effects of poverty alleviation policies (Musiliu O. Oseni, Michael G. Pollitt, David M. Reiner, et al, 2013). 


\section{Survey Overview}

Field research. The fieldwork for the survey-which was conducted by graduate students and staff from Agricultural University of Hebei after a professional survey training-involved two distinct stages: pilot survey and main survey.

The team conducted field research at the selected 513 colleges in all of the 171 counties/ districts in Hebei province where rural residents live at. For showing the distinct deviation of energy consumption, the whole respondents are divided into two groups: counties(including county-level city, Autonomous county and county) with poverty alleviation task or common counties. For Hebei province, there are two levels of counties which were identified as key counties for national poverty alleviation and development work(CNPAs) or provincial poverty alleviation and development work(CPPAs). Furthermore, depending on the difference of natural circumstance, CNPAs can be divided into two sets: CNPAs of internal Yanshan - taihang mountain region(CNPAs_I) and CNPAs of external Yanshan-taihang mountain region(CNPAs_E).

For each county the survey is conducted following same procedure: issuing a questionnaire to the relevant competent authorities and having face-to-face interviews (For example, local power authorities, local rural work communities), helping residents with a face-to-face questionnaire.

Such kind of works were carried out and the results have been published before ( Zhang, Wei, Qin, et al,2014; Yue,Long,Chen.2013).The survey sample consisted of 5130 interviews carried out during July and August 2014 and in January 2015 and with general well work. The whole survey covered all of the counties simultaneously to support a comparative study on the habit and attitude for rural residents' energy consumption.

Region description. The survey objective counties are divided into 4 sets (CCs is omitted) and all results of survey will be shown as such classification in table 1 .

Table 1. The List of poverty alleviation counties in Hebei.

\begin{tabular}{|c|c|c|}
\hline Set & County/County-level city/Autonomous city county & Number \\
\hline CNPAs_I & $\begin{array}{c}\text { Xuanhua, Zhangbei, Kangbao, Guyuan, Shangyi, Yuxian, Yanyuan, } \\
\text { Huaian,Wanquan, Fuping, Tangxian, Laiyuan, Shunping, Laishui, } \\
\text { Wangdu, Yixian, Quyang, Chengde county, Pingquan, Longhua, } \\
\text { Fengning, Weichang }\end{array}$ & 22 \\
\hline CNPAs_E & $\begin{array}{c}\text { Xingtang, Lingshou, Zanhuang, Pingshan, Qinglong, Daming, } \\
\text { Weixian, Lincheng, Julu, Xinhe, Guangzong, Pingxiang, Weixian, } \\
\text { Chicheng, Chongli, Luanping, Haixing, Yanshan, Nanpi, Wuyi, } \\
\text { Wuqiang, Raoyang, Fucheng }\end{array}$ & 22 \\
\hline CPPAs & $\begin{array}{c}\text { ianxian, Mengcun, Guangping, Dongguang, Zhuolu, Guantao, } \\
\text { Gucheng, Zaoqiang, Boye, Nanhe, Jize,Renxian,Wuqiao, Feixiang, } \\
\text { Neiqiu, Linxi, Xilong }\end{array}$ & 17 \\
\hline Total & & 62 \\
\hline
\end{tabular}

Descriptive statistics of the sample. The process of surveying the rural household energy consumption is synchronized with all sets of counties. A description of the sample is shown in Table 2. Most of the items are similar or have fine differences in the numbers, but the age structure of respondents in different sets shows obvious difference: the young respondents(18-39) are more than half of total population in GCs while the corresponding parts in CNPAs_E and elder (60\& above) in CPPAs are middle-aged(40-59). 
Table 2. The descriptive statistics of sample.

\begin{tabular}{|c|c|c|c|c|c|}
\hline & \multirow{2}{*}{ category } & \multicolumn{4}{|c|}{ Share in survey (\%) } \\
\hline & & CNPAs_I & CNPAs_E & CPPAs & $\mathrm{CCs}$ \\
\hline \multirow{2}{*}{ Gender } & Male & 72.61 & $78.62 \%$ & $79.63 \%$ & $71.35 \%$ \\
\hline & female & $27.39 \%$ & $21.38 \%$ & $20.37 \%$ & $28.65 \%$ \\
\hline \multirow{3}{*}{ Age } & $18-39$ & $13.51 \%$ & $16.38 \%$ & $14.91 \%$ & $54.60 \%$ \\
\hline & $40-59$ & $42.34 \%$ & $63.79 \%$ & $30.43 \%$ & $29.75 \%$ \\
\hline & 60\&over & $44.14 \%$ & $19.83 \%$ & $54.66 \%$ & $15.65 \%$ \\
\hline \multirow{3}{*}{$\begin{array}{c}\text { Family } \\
\text { population }\end{array}$} & $1-2$ & $20.47 \%$ & $19.34 \%$ & $11.11 \%$ & $13.33 \%$ \\
\hline & $3-5$ & $62.03 \%$ & $65.68 \%$ & $70.16 \%$ & $65.27 \%$ \\
\hline & 6\&over & $17.50 \%$ & $14.98 \%$ & $18.72 \%$ & $21.40 \%$ \\
\hline \multirow{5}{*}{ education } & Unschooled & $4.43 \%$ & $8.21 \%$ & $2.52 \%$ & $3.97 \%$ \\
\hline & $\begin{array}{c}\text { Elementary } \\
\text { school }\end{array}$ & $27.21 \%$ & $22.59 \%$ & $19.54 \%$ & $22.21 \%$ \\
\hline & Middle school & $45.08 \%$ & $48.50 \%$ & $55.46 \%$ & $49.86 \%$ \\
\hline & High school & $16.72 \%$ & $13.74 \%$ & $14.08 \%$ & $17.52 \%$ \\
\hline & College \& above & $4.92 \%$ & $6.95 \%$ & $8.40 \%$ & $6.44 \%$ \\
\hline \multirow{7}{*}{ occupation } & Planting & $61.90 \%$ & $64.64 \%$ & $46.57 \%$ & $48.44 \%$ \\
\hline & Breeding & $6.20 \%$ & $5.07 \%$ & $0.70 \%$ & $2.62 \%$ \\
\hline & Foresting & $3.61 \%$ & $4.20 \%$ & $5.10 \%$ & $3.90 \%$ \\
\hline & Aquaculture & $1.15 \%$ & $0.72 \%$ & $0.70 \%$ & $1.50 \%$ \\
\hline & Business & $4.91 \%$ & $3.91 \%$ & $8.79 \%$ & $7.51 \%$ \\
\hline & Labor work & $14.72 \%$ & $12.32 \%$ & $24.96 \%$ & $23.88 \%$ \\
\hline & others & $7.50 \%$ & $9.13 \%$ & $13.18 \%$ & $12.15 \%$ \\
\hline
\end{tabular}

\section{Main Results}

The Concern about Power Supply. Because of the incidents of circuit inspection, lack of power load in peak hours, or unpredictable line faults, power supply may take on service interruption or low-voltage that will cause the discontent of rural residents. Fig 1 shows that power supply quality and reliability has consistent results to the level of development of local economy. But the residents' degree of concern on power consumption of electrical appliance takes a reversed sequence( As in Fig. 2).

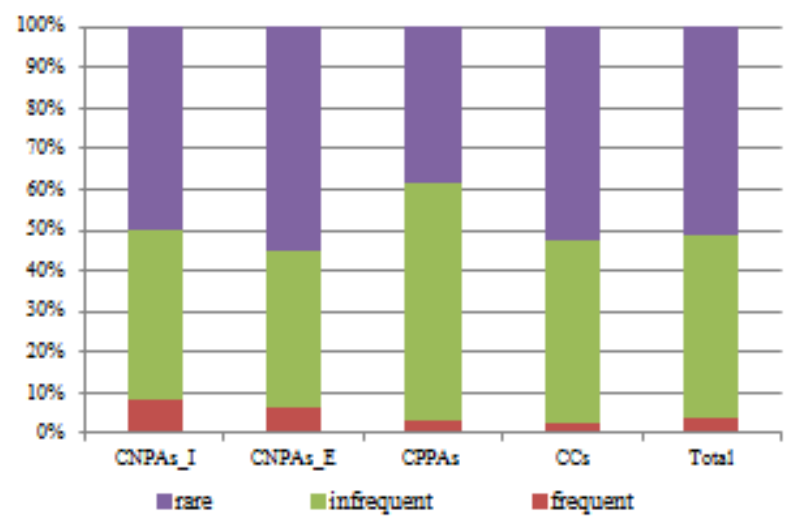

Fig.1 Stability of power supply

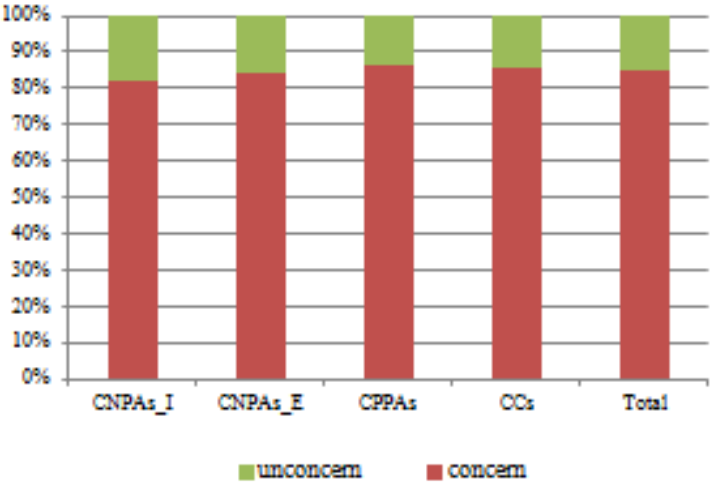

Fig.2 Concern on power consumption of appliance

The Concern about the Raise of Power Price. Because of the respondents' cognition of the questionnaire, we choose a four-option mode instead of typical five-option mode on the degree of concern about the raise of power bills that is extremely, fairly, a little, and negligibly. Less than $4 \%$ of all respondents negligibly concern the raise of the power bills and there are no distinctly differences on this topic between the four sets. The respondents of CCs $(57.78 \%)$ consider the raise of power price fairly at the top level of all the sets, followed by CNPAs_I (53.17\%), CPPAs $(51.16 \%)$, and CNPAs_E(46.01\%). For the choice of "extremely concern about the power 
price" , $31.46 \%$ of respondents in CNPAs_E say "yes" and followed by CNPAs-I(26.98\%), CPPAs(22.74\%), and CCs (21.58\%).Such opinion can be found in other scholars' research that less information and guidance on energy saving led to inefficient electricity saving behaviors of respondents in Chongqing( Guo, Philip, Zhang ,2013).

\section{Conclusions}

Contrary to common sense, people in poverty alleviate counties do not pay more attentions to the power consumption of devices than common counties people. But for the power service level the rate of respondents in common regions expresses their discontentment less than in poverty alleviate counties.

In the three types of poverty alleviate counties, the background information are more similar than that of common counties respondents in a random survey process. But the opinions of power consumption shows some degree of difference without an apparent interpretation. Further research should be continued to give more details of relationship between different regions or different homes on economic level.

For the item "opinion on the raise of power price", the difference choices between four sets of respondents existed but there are no obvious line between common and poverty alleviate counties. Such results may give recommendations to poverty alleviation policy that the focus of targeted poverty alleviation should be poor families instead of economically backward counties.

\section{Acknowledgements}

This work is supported by "The development of social science research project in Hebei provinceAnalysis on the structure of rural hou sehold energy consumption in Hebei”, (No. 2015031220).

\section{References}

[1] Jean-Francois Rischard. Rural Energy and Development for Two Billion People. http://documents.worldbank.org/curated/en/807141468330923341/pdf/760760WP0Rural0ment0dat e02005003007.pdf.

[2] Musiliu O Oseni, Michael G Pollitt, David M Reiner, et al. 2013 EPRG Public Opinion Survey: Smart Energy - Attitudes and Behaviours. Cambridge Working Papers in Economics.

[3] Xinye Zhang, Chu Wei, Ping Qin, Jin Guo, Yihua Yu, Feng Song, Zhangming Chen. Characteristics pf residential energy consumption in China: Findings from a household survey[J]. Energy Policy, 75(2014) 126-135.

[4] Ting Yue, Ruyin Long, Hong Chen. Factors influencing energy-saving behavior of urban households in Jinagsu Province[J]. Energy Policy 62(2013)665-675.

[5] Guo Ma, Philip Andrews-Speed, Jiandong Zhang. Chinese consumer attitudes towards energy saving: The case of household electrical appliances in Chongqing[J]. Energy Policy 56(2013):591602. 